\title{
Two Distinct Types of ON Directionally Selective Ganglion Cells in the Rabbit Retina
}

\author{
Hideo Hoshi, Lian-Ming Tian, Stephen C. Massey, and Stephen L. Mills ${ }^{\star}$ \\ Department of Ophthalmology and Visual Science, University of Texas at Houston, Houston, \\ Texas, USA
}

\begin{abstract}
Mammalian retinas contain about 20 types of ganglion cells that respond to different aspects of the visual scene, including the direction of motion of objects in the visual field. The rabbit retina has long been thought to contain two distinct types of directionally selective (DS) ganglion cell: a bistratified ON-OFF DS ganglion cell that responds to onset and termination of light, and an ON DS ganglion cell, which stratifies only in the ON layer and responds only to light onset. This division is challenged by targeted recordings from rabbit retina, which indicate that ON DS ganglion cells occur in two discriminably different types. One of these is strongly tracer-coupled to amacrine cells; the other is never tracer-coupled. These two types also differ in branching pattern, stratification depth, relative latency, and transience of spiking. The sustained, uncoupled ON DS cell ramifies completely within the lower cholinergic band and responds to nicotine with continuous firing. In contrast, the transient, coupled ON DS ganglion cell stratifies above the cholinergic band and is not positioned to receive major input from cholinergic amacrine cells, consistent with its modest response to the cholinergic agonist nicotine. Much data have accrued that directional responses in the mammalian retina originate via gamma-aminobutyric acid (GABA) release from the dendrites of starburst amacrine cells (Euler et al., 2002). If there is an ON DS ganglion cell that does not stratify in the starburst band, this suggests that its GABAdependent directional signals may be generated by a mechanism independent of starburst amacrine cells.
\end{abstract}

\section{INDEXING TERMS}

bipolar cell; amacrine cell; gap junction

\begin{abstract}
Understanding of visual processing depends on determining the contributions of the 20 or so types of retinal ganglion cells that independently sample the retina and send their outputs in parallel streams to the rest of the brain (Masland, 2001; Wässle, 2004). One critically important perceptual stream is the detection of object motion. The presence of ganglion cells in the mammalian retina which are differentially sensitive to the direction of motion has been known for nearly 50 years (Barlow et al., 1964). Traditionally, these have been divided into two types: ON-OFF directionally sensitive (DS) ganglion cells, which are bistratified narrowly in the ON and OFF cholinergic bands (Amthor et al., 1984; Famiglietti, 1992) and which respond to both the onset and offset of moving edges, and an ON DS type, which stratifies only in the ON cholinergic band and responds only to the leading edge of a bar of light (Amthor et al., 1989; Famiglietti, 1992).
\end{abstract}

(C) 2011 Wiley-Liss, Inc.

"CORRESPONDENCE TO: Stephen L. Mills, Department of Ophthalmology and Visual Science, University of Texas at Houston, 6431 Fannin, MSB 7.024, Houston, TX 77030. Stephen.L.Mills@uth.tmc.edu. 
ON-OFF DS ganglion cells have been much more frequently studied than ON DS ganglion cells. ON-OFF DS ganglion cells contain four subtypes with different axes of preferred direction (Oyster and Barlow, 1967), while ON DS ganglion cells are comprised of three subtypes according to their preferred directional axes (Oyster, 1968). ON DS ganglion cells also differ from ON-OFF DS ganglion cells in that their directional sensitivity is seen at slower speeds of motion (Oyster, 1968). This study provides evidence that there are two distinctly different types of ON DS ganglion cells, each of which contain members that respond to the same three axes of preferred motion. These two types of ON DS ganglion cell can be distinguished by numerous consistent differences in their morphology, physiology, and tracer coupling patterns.

One type of ON DS ganglion cell we have stained resembles that recently characterized by Ackert et al. (2006, 2009), while the other type has been shown in studies by Buhl and Peichl (1986) and Kanjhan and Vaney (2008) and perhaps many others where exact correspondence is more difficult to determine. Our findings are in agreement with and extend those reported in a previous brief report (Mills and Hoshi, 2010) and a recent article by Kanhjan and Sivyer (2010).

\section{MATERIALS AND METHODS}

Adult albino rabbits were deeply anesthetized with injections of urethane $(1.5 \mathrm{~g} / \mathrm{kg}$ intraperitoneally), then humanely killed by intracardial injection of $5 \mathrm{cc}$ urethane following removal of the eyes. All procedures were in accordance with the guidelines of the University of Texas at Houston Animal Welfare Committee. Some retinas were removed from the sclera and placed on a black membrane filter, ganglion cell side up, inserted into a perfusion chamber (Warner Instruments, Hamden, CT) and then placed on the stage of an Olympus BX50WI upright epifluorescent microscope. Other retinas were cut into pieces and placed into the perfusion chamber with the sclera attached. The tissue was superfused during the experiment with Ames medium (Sigma-Aldrich, St. Louis, MO) bubbled with 95\% $\mathrm{O}_{2} / 5 \%$ $\mathrm{CO}_{2}$.

\section{Cell targeting and injection}

Ganglion cells were stained by application of a few drops of the nuclear fluorescent stain acridine orange (Invitrogen, Carlsbad, CA) dissolved in Ames medium (Sigma-Aldrich) and applied to the retina as needed to visualize the ganglion cell population. With experience, several ganglion cell classes can be targeted, including the two types described in this study. The ON DS ganglion cells have medium large, slightly ovular somas with nuclei that fill about half the soma. For one of the types, the contrast between the cytoplasm and nucleus, which is usually in the middle of the cell, often gives the cell a crescent appearance (Ackert et al., 2006), while the nucleus in the other type is more often located at one end of the soma.

\section{Electrophysiology and intracellular staining}

Loose patch recordings were made with $1.2 \mathrm{~mm}$ borosilicate glass pulled to a resistance of 4-6 M $\Omega$ on a Brown-Flaming horizontal micropipette puller (Sutter Instruments, Novato, CA, P-97) and filled with Ames medium and $0.2 \%$ pyranine (Sigma-Aldrich). Recordings were made with an NPI EPC-03X amplifier (ALA Scientific, Westbury, NY) at 1,000× gain and notch filtered at $60 \mathrm{~Hz}$. Data was acquired and analyzed using Experimenter 5.0 (DataWave Technology, Berthoud, CO). Recorded cells were filled with Neurobiotin using a sharp electrode as described below. 
For intracellular staining, thinwall glass microelectrodes were tip-filled with $0.5 \%$ Lucifer Yellow-CH (L-453, Invitrogen) and 3.5\% Neurobiotin (Vector Labs, Burlingame, CA) in 50 $\mathrm{mM}$ phosphate buffer (PB) and backfilled with $3 \mathrm{M} \mathrm{LiCl}$. Lucifer Yellow was iontophoresed with $1 \mathrm{nA}$ negative current for a few seconds to verify cell penetration, then each ganglion cell was filled with Neurobiotin ( $+1 \mathrm{nA}, 3 \mathrm{~Hz}, 10$ minutes). Following injection, the tissue was superfused for at least an additional 30 minutes, then fixed in $4 \%$ paraformaldehyde in $0.1 \mathrm{M}$ phosphate-buffered saline (PBS), $\mathrm{pH} 7.4$, for 1 hour at room temperature. Cells were visualized by overnight incubation in 1:1,000 streptavidin-Cy3 (Jackson ImmunoResearch, West Grove, PA). Tissue was mounted in 50\% 0.2M PBS $+50 \%$ glycerol $+0.1 \%$ paraphenylenediamine (Sigma) to retard fading by fluorescent illumination.

\section{Visual stimulation}

Each ganglion cell was stimulated with spots, annuli, and moving bars imaged on a Lucivid monitor (Micro-BrightField, Williston, VT) and projected through a $4 \times$ objective on the retina through using custom routines written in MatLab (MathWorks, Natick, MA) and the Psychophysics Toolbox (Brainard, 1997; Pelli, 1997). Pieces of retina were always placed with the visual streak oriented in the same direction so that directional preferences could be reliably recovered. Receptive field sizes were mapped by flashing spots of light ranging from $30-900 \mu \mathrm{m}$ in diameter. Differential sensitivity to direction of motion was determined by moving $50 \mu \mathrm{m}$ width bars across the receptive field at orientation intervals of $22.5^{\circ}$ or $45^{\circ}$ at a speed of $200 \mu \mathrm{m} \mathrm{sec}^{-1}$.

\section{Immunohistochemistry}

For triple-labeling, some retinas were blocked with 3\% donkey serum (Jackson) / $0.1 \%$ sodium azide / 0.1M PBS for 90 minutes at room temperature and incubated in primary antibodies with $0.1 \mathrm{M}$ PBS / $0.1 \%$ sodium azide / $0.3 \%$ Triton $\mathrm{X}-100$ for 7 days at $4{ }^{\circ} \mathrm{C}$. Then tissues were rinsed several times in $0.1 \mathrm{M}$ PBS and reincubated in the secondary antibody overnight at $4^{\circ} \mathrm{C}$. Donkey antimouse Cy3 and donkey antigoat Cy5 (Jackson, 1:200) and donkey antirabbit Alexa488 (Invitrogen, 1:200) were used as secondary antibodies.

\section{Antibody characterization}

An antibody to choline acetyltransferase (ChAT; 1:100; Millipore, Billerica, MA; immunogen $=$ human placental enzyme) was used as a guide in establishing depth of stratification, while an antibody to GABA raised as a formaldehyde conjugate to porcine thyroglobulin (Immunosolution, Jesmond, NSW, AU; 1:1,000) was used to test for the transmitter identity of the coupled amacrine cells (Table 1). The specificity of the ChAT antibody was tested previously by western blot analysis of brain protein extracts from rat and a variety of fish (Anadón et al., 2000) and showed bands of 68-72 kDa. All bands disappeared when the primary antibody was preincubated with human placental ChAT.

The GABA antibody was prepared by formaldehyde-conjugation of GABA to the carrier protein porcine thyroglobulin. The antibody was reported by the manufacturer to recognize GABA, but not formaldehyde-conjugates of other amino acids transmitters in dot blots, nor glutaraldehyde conjugates of GABA (Pow et al., 1995). It also recognized previously established GABA-containing, but not glycine-containing, neurons in a variety of tissues. Hoshi and Mills (2009) also showed that preadsorption with porcine thyroglobulin (SigmaAldrich) did not alter the pattern and intensity of anti-GABA immunostaining, indicating that possible clones recognizing the carrier protein did not contribute false-positives to the analysis. 


\section{Confocal microscopy and quantitative analysis}

Fluorescent images of stained material were acquired using a Zeiss LSM 510 confocal microscope. Images were scanned as $0.3-\mu \mathrm{m}$ optical sections; stacks of these images were constructed as needed and specified in the figures. Intensity adjustments were made in Adobe Photoshop (Adobe Systems, San Jose, CA). Quantitative measurements of area and distance were made in SigmaScan Pro (SPSS, Chicago, IL). An ImageJ (NIH, Bethesda, MD) plugin was used to perform Sholl analyses on images of individual cells (Sholl, 1953). This consisted of drawing concentric circles at 10- $\mu \mathrm{m}$ intervals from the center of the soma, then counting the number of intersections of dendrites with the circles. Axons and coupled cells were selected in Adobe Photoshop and their intensities set to background values so as to leave only the dendritic structure of the cells visible. The distance scale in each image was normalized by the radius of the cell so that cells stained at different eccentricities could be compared meaningfully. Coupled ON DS ganglion cells were not used if the dendrites of the coupled amacrine cells were stained brightly and could therefore not be reliably thresholded from the image.

Firing rates were measured as a function of the visual stimulation by constructing peristimulus time histograms in DataWave (SciWorks, Loveland, CO). A measure of transience was calculated as the difference in firing rate in the second half of the 400-ms stimulus divided by the firing rate in the first half. Larger numbers indicate more sustained firing rates. An index of the strength of directional selectivity (DSI) was computed by relating the relative spike rates of the preferred $(p)$ and null $(n)$ directions according to the formula DSI $=(p-n) /(p+n)$. This index ranges from 0 for no DSI to 1 when there is no spiking at all in the null direction.

Receptive fields were plotted for each cell type by measuring the number of spikes in response to spots of increasing diameter. To adjust for differences in size due to retinal location, receptive field sizes were normalized by the dendritic field size as measured by Neurobiotin staining following recording. Means and standard deviations were calculated following rounding the normalized spot size data to the nearest 0.25 multiple of the radius. The number of spikes was normalized by that of the best spot for each cell.

\section{RESULTS}

We stained and/or recorded from a large number of ganglion cell types in the rabbit retina visualized with acridine orange solution. Two different types of ganglion cells with ON physiology and with sensitivity to the direction of motion of moving slits of light were found. Staining of these cells via Neurobiotin injection revealed two distinctly different morphologies that correlated with the differences in their physiological responses.

\section{Tracer coupling}

The most salient difference between the two types of ganglion cells lay in their relative patterns and incidences of coupling to amacrine cells (Fig. 1). One type (left) was Neurobiotin-coupled to two populations of amacrine cells, while the other type never showed coupling. While there was of course some variation in the number of amacrine cells coupled to the coupled type, there was no overlap between types. The uncoupled type (Fig. 1 , right; $n=52$ ), whose distinctive morphological and physiological differences can by themselves distinguish it from the coupled type, was always completely uncoupled. The coupled type $(n=45)$ was never coupled to fewer than 60 amacrine cells (mean $=102$ cells, standard deviation $[\mathrm{SD}]=30.4 ; \max =190$ ). We frequently stained pairs of the two types in close proximity to minimize changes in the state of the retina and differences in retinal location; the coupling patterns remained consistent in these close pairs. In agreement with 
Ackert et al. (2006) and Kanhjan and Sivyer (2010), little to no coupling was seen from coupled ON DS ganglion cells to neighboring coupled ON DS ganglion cells, although such homologous coupling was seen in three cases with 2-5 neighboring ganglion cells each.

The amacrine cells stained following iontophoresis of Neurobiotin into the coupled ON DS ganglion cell comprised two separate populations. One, as reported by Ackert et al. (2006, 2009), is an axon-bearing amacrine cell. Figure 2A shows an example of a coupled ON DS ganglion cell where the axon-bearing amacrine cells are well stained; three of these are indicated with arrows. The initial processes of this cell costratify with the dendrites of the coupled ON DS ganglion cell, but Ackert et al. (2009) report that the most distal processes also ascend to stratify in the OFF cholinergic band. Figure 2B is a montage of micrographs showing five amacrine cells coupled to an ON DS ganglion cell which was injected with Popro1 (Hoshi et al., 2006). Following diffusion of the fluorescent Popro1 into the amacrine cells, five of the many Popro1-fluorescent amacrine cells were injected with Neurobiotin. All of these were of the axon-bearing type, which was more intensely stained via the Popro1-coupling method. A similar set of Neurobiotin injections was made into 14 axonbearing amacrine cells following Popro1-staining of another ON DS ganglion cell. One hour of diffusion time was allowed before fixation. A portion of this figure is shown in the inset to Figure 2B. The results show numerous Neurobiotin-coupled amacrine cells in the vicinity of an injected cell, indicating that this type of amacrine cell is well coupled to its neighbors.

The second amacrine cell type is diffusely stratified and fills most of the inner plexiform layer (IPL) from the most distal portion down to, but not including, the ON cholinergic band (Fig. 3A). We again obtained more complete views of this cell by injecting coupled ON DS ganglion cells with PoPro1. Following diffusion of the Popro1, we injected Neurobiotin into this multistratified amacrine cell (Fig. 3B,C).

Both of these amacrine cell types were identified as GABA-positive (Fig. 4A,B) following incubation with an antibody to GABA (Pow et al., 1995). We quantified the differences in size and GABA content by digital analysis in SigmaScan Pro. Coupled amacrine cells in a $110 \times 110 \mu \mathrm{m}$ micrograph were identified by the presence of Neurobiotin. We then measured the area and GABA staining intensity of each coupled cell. Figure 4C shows that the amacrine cell population fell into low and high clusters according to GABA content. The calculated diameter of these cells was different between the two groups. The mean diameter of the low GABA content group, which could be matched with the morphology of the axonbearing amacrine cell due to the presence of pronounced apical dendrites (see arrowed amacrines in Fig. 2A), was $8.7 \mu \mathrm{m}(n=19 ; \mathrm{SD}=0.58)$. The mean diameter of the high GABA content group, which corresponds to the multistratified amacrine cells, was $9.72 \mu \mathrm{m}$ $(n=17 ; \mathrm{SD}=0.58)$. These diameters were significantly different $(t=4.98 ; \mathrm{df}=34 ; P<$ $0.001)$. At $\approx 6 \mathrm{~mm}$ ventral to the visual streak, the multistratified amacrine cells averaged 7.7 $\times 10.5 \mu \mathrm{m}$ on their short versus long diameters. The similarity in number of cells (19 of the axon-bearing types, 17 of the multistratified) in this area suggests that their densities are similar.

Coupling between multistratified amacrine cells was weak to absent following Neurobiotin injection into the Popro1-labeled amacrine cell soma. At most, 2-5 poorly stained somas could be found in the vicinity. When compared to the intense staining of the multistratified amacrine cells following Neurobiotin injection into the coupled ON DS ganglion cell (Fig. $4 \mathrm{D})$, it suggests that these amacrine cells are well coupled to the ganglion cell, but poorly coupled to one another. In a prior study that modeled tracer movement among the different cell types of a ganglion cell-amacrine cell coupled network, we found that when amacrine cells are well coupled to their neighboring amacrine cells, the mosaic of stained amacrine cells often extends well beyond the dendritic field of the injected ganglion cell if sufficient 
diffusion time is permitted (Mills et al., 2007). The fact that multistratified amacrine cell somas were restricted to the dendritic area of the injected ganglion cell further suggests that homologous coupling is weak between the amacrine cells of this type.

\section{Stratification}

The dendrites of the ON DS ganglion cell, like the ONOFF DS type, have been reported to ramify in the proximal cholinergic band, which lies at about 70\% depth (Famiglietti, 1992). In our study, the uncoupled ON DS ganglion cell type stratifies at the same depth as the dendrites of the ON cholinergic amacrine cells, while the coupled type ramifies slightly more distal to the processes of the ON-OFF DS ganglion cell and the ON cholinergic band, as stained by an antibody to choline acetyltransferase. This difference is visible in the zreconstructions shown in Figure 5. The uncoupled ON DS ganglion cell ramifies within the ON cholinergic band (Fig. 5A), while the coupled ON DS ganglion cell ramifies slightly distal to the ON ChAT band (Fig. 5B.) This is seen even more clearly in Figure 3A, where a single dendrite of a Neurobiotin-injected coupled ON DS ganglion cell lies atop the ON cholinergic band, with the coupled multistratified amacrine cell contiguous and above.

We also compared the dendritic stratification of the two ON DS ganglion cell types relative to the ChAT band in flatmount view. Figure 6A-J shows $0.3-\mu \mathrm{m}$ optical sections taken at depths from the ganglion cell layer (A,F) to just distal to the ON cholinergic band (E,J). The ganglion cell dendrites (magenta) on the left (C,D) belong to an uncoupled ON DS ganglion cell, while those on the right $(\mathrm{I}, \mathrm{J})$ emanate from a coupled ON DS ganglion cell. It can clearly be seen that the dendrites of the uncoupled cell (left) are contained within the ON ChAT band (C,D), while those of the coupled cell primarily lie just distal to this band (J).

Figure 6C,D also shows that the dendrites of the uncoupled ON DS ganglion cell closely cofasciculate with the cholinergic processes, while the dendrites of the coupled ON DS ganglion cell do not cofasciculate (Fig. 6I,J). The dendrite in the left side of panel J crosses a large area without any cholinergic processes, while a possible cofasciculation on the right side is illusory, as this slightly out-of-focus portion of the dendrite ramifies well above the cholinergic band. If it were in the cholinergic band, it would be visible in panel I; this dendrite stratifies even more distal to the cholinergic band and beyond the focal series in the figure.

The difference in stratification depth, although small, was reliable. We measured the stratification depth as a percentage of the IPL in z-rotations of the two cell types. The mean depth of the coupled ON DS ganglion cell dendrites was $57 \%(\mathrm{SD}=3.7 \% ; n=5)$. The mean depth of the uncoupled ON DS ganglion cells was $77 \%(\mathrm{SD}=5.0 \% ; n=3$ ). The middle of the ChAT bands averaged $20 \%$ and $74 \%$ depth of the IPL. For an average IPL width of 15 $\mu \mathrm{m}$, the average distance between the coupled and coupled ON DS dendrites would be 15 $\mu \mathrm{m} \times(77 \%-57 \%)=3 \mu \mathrm{m}$. To further confirm this difference, we closely examined dendritic crossings in overlapping cell pairs to establish relative depth. We examined not only overlapping dendrites in uncoupled versus coupled ON DS dendritic crossings, but also overlapping dendrites between ON-OFF DS ganglion cells and each type of ON DS ganglion cell. In four cell pairs containing dendrites from coupled ON DS ganglion cell crossing dendrites from an uncoupled ON DS ganglion cell, the dendrites of the coupled ON DS ganglion cell lay distal to those of the uncoupled ON DS ganglion cell 100\% of the time (31/31). Dendrites of the coupled ON DS ganglion cell also lay distal to processes of ONOFF DS ganglion cells $100 \%$ of the time (9/9; two cell pairs), while dendrites of the uncoupled ON DS ganglion cell most often lay proximal to dendrites of ON-OFF DS ganglion cells (11/13; two cell pairs). 
The relative positions of the uncoupled type of ON DS ganglion cell was therefore consistent with that of ON DS ganglion cells reported by Famiglietti (1992), in that its dendrites generally lay proximal to those of ON-OFF DS ganglion cells. The 3- $\mu \mathrm{m}$ difference in stratification proved absolutely reliable in predicting relative depth in direct comparisons of the two ON DS ganglion cell types, and also reliable in the cases where ONOFF DS ganglion cells provided a comparative marker. Famiglietti (1992) also noted that the estimates of stratification depth for MTN-projecting (ON DS) ganglion cells by Buhl and Peichl (1986) were at 60\% IPL depth, while his estimates of the ON-OFF DS ganglion cells stratification depth was at 75\%. Vaney et al. (1989) also reported that ON DS ganglion cells ramified at 60\% depth, higher than the ON cholinergic band and ON-OFF DS ganglion cells. It should be noted, however, that the Buhl and Peichl (1986) study might include both of our putative ON DS ganglion cell types, thereby containing cells which could ramify at both depths. Figure 1 from Ackert et al. (2009), which shows a z-rendering of one of their coupled ON DS ganglion cell types, also appears to lie slightly above the ON cholinergic band.

\section{Differences in branching pattern}

There are several morphological differences in the two types of ON DS ganglion cell. Figure 7 shows neighboring ON DS ganglion cells of both types. The coupled amacrine cells were removed from the cell on the right using the clone stamp tool in Adobe Photoshop solely to produce an unobscured comparison of the dendritic branching patterns. Some immediate qualitative differences then become readily apparent. For example, the order of branching is higher in the uncoupled cell (left) than in the coupled cell. There are considerably more large regions of "open" space in the coupled cell (right), while the frequent branching of the uncoupled cell produces more numerous, but smaller regions not containing branches. Branch angles $>60^{\circ}$ were common in the uncoupled cell, but not in the coupled type. Kanjhan and Sivyer (2010) also showed differences in number and mean length of the terminal dendrites of the two types.

We employed three quantitative measures that reflected the qualitative differences between the cells and applied them to images from 45 coupled and 51 uncoupled ON DS ganglion cells restricted to the inferior retina to minimize variability. First, we performed a Sholl analysis (1953) using ImageJ, which provides a measure of dendritic density by counting intersections of dendrites with annuli drawn at regular distances from the soma. The results (Fig. 8A) clearly illustrate the greater dendritic density of the uncoupled ON DS ganglion cells compared to the coupled type. We also counted the number of retroflexive terminal processes, which were defined as final branches whose termination point lay closer to the soma that their initiation point. There were an average of $2.4 \pm 1.7$ (mean $\pm 1 \mathrm{SD}$ ) retroflexive processes in coupled ON DS ganglion cells, compared to $14.7 \pm 5.5$ such processes in the uncoupled ON DS ganglion cell $\left(t\left(94_{\mathrm{df}}\right)=14.52, P<0.001\right)$. We also counted the number of times two dendrites from the same cell crossed one another. These averaged $4.6 \pm 3.3$ in the coupled cell versus $16.5 \pm 6.1$ in the uncoupled cell $\left(t\left(94_{\mathrm{df}}\right)=\right.$ $11.71, P<0.001)$. Most of these few crossings in the coupled cell were in the far distal area of the dendritic tree. Figure 8B shows a scattergram of these two measures that produces complete separation between the populations, as classified by the binary coupled/uncoupled parameter. Several cells representing the range of variability in the literature are also plotted on this figure (see legend) and suggest that both types have previously been encountered.

\section{Relative sizes}

The two types of ON DS ganglion cell were comparable in size (Figs. 1, 7). Figure 8C compares the dendritic area of all of the injected cells of each type. The uncoupled type was usually larger than the coupled type; this size difference increased with eccentricity from 
near equality within $2 \mathrm{~mm}$ of the visual streak, and then increased regularly from $10 \%$ larger at $2-3 \mathrm{~mm}$ ventral to $18 \%$ higher from $4-10 \mathrm{~mm}$ ventral to the visual streak, corresponding to an average $8.6 \%$ difference in dendritic radius for the uncoupled over the coupled type. The increase in dendritic area with eccentricity was reasonably well fit by least squares linear regression for both the uncoupled (solid line, filled triangles) and the coupled ganglion cells (dashed line, unfilled circles).

The area data of Buhl and Peichl (1986; dotted line) was distributed similarly. An analysis of variance was performed on the linear regressions of our two groups and also the data of Buhl and Peichl. Because no ON DS ganglion cells were stained in our study at $<1.75 \mathrm{~mm}$ ventral to the visual streak, this range of eccentricities was deleted from the Buhl and Peichl (1986) data for the statistical comparison. The results indicated that dendritic area was not significantly different between any of the groups $(P>0.1)$. However, the slopes $\left(\mathrm{mm}^{2}\right.$ area/ $\mathrm{mm}$ distance from visual streak) of the Buhl and Peichl data (0.0567) and the uncoupled ON DS ganglion cells $(0.0605)$ were significantly different $(P<0.001)$ from the slope of the coupled ON DS ganglion cells (0.0503). The slopes of the ganglion cells stained by Buhl and Peichl and our uncoupled ON DS ganglion cells were not significantly different from one another $(P>0.1)$. This is an indication of greater similarity between the Buhl and Peichl (1986) cells and our uncoupled cells, which more closely resemble the representative cells of Buhl and Peichl than do the coupled cells in size, morphology, and size trend across the retina.

Figure 9, which shows four proximate coupled ON DS ganglion cells and an ON-OFF DS ganglion cell (white), indicates that the coupled ON DS ganglion cells are all larger than the neighboring ON-OFF DS ganglion cell. We did not study ON-OFF DS ganglion cells as a population, but on those occasions when an ON-OFF DS ganglion cell was filled adjacent to one of the ON DS ganglion cell types, the ON-OFF DS ganglion cell was always smaller, as in Figure 9. (The amacrine cells coupled to the yellow cell, although numerous, are much dimmer than those of the other three coupled ON DS ganglion cells and are not easily seen in this micrograph.) It is unlikely that all of the coupled ON DS ganglion cells in this area were filled, so that the amount of overlap cannot be estimated from this figure.

\section{Physiological differences}

We established loose patch recordings and subsequently stained 14 examples of each type of ON DS ganglion cell. Besides the morphological differences detailed above, there were regular differences in the response properties of the two ON DS ganglion cell types in response to flashes of light and moving bars. First, the uncoupled cell was sluggish, with latencies $>350 \mathrm{~ms}$ for large spots, while the more distal, coupled cell responded about $75 \mathrm{~ms}$ following onset of spots of light (Fig. 10A). Using a sustained/transience index (see Materials and Methods), Figure 10B shows that the uncoupled ON DS ganglion cell was significantly more sustained than the more transient coupled ON DS ganglion cell $(t=$ $11.498, \mathrm{df}=20, P<0.001)$. Similarly, the difference between latency to peak response was much longer $(t=25.2, \mathrm{df}=16, P<0.01$; not shown in figure) for the sustained uncoupled ON DS ganglion cell $(381.0 \mathrm{~ms} \pm 49.3 \mathrm{SE})$ than for the transient coupled type $(70.7 \pm 7.7$ $\mathrm{ms})$.

Receptive field sizes were determined by responses to spots of increasing size, then normalized by dendritic field size measured following staining as described in Materials and Methods. Figure 10C shows that the optimal spot size for transient coupled ganglion cells peaked at approximately the dendritic field radius and declined thereafter. This is similar to the findings of Ackert et al. (2009). In contrast, the optimal spot size for sustained uncoupled ganglion cells was smaller than the dendritic field area; the response to larger spots progressively became smaller. 
Nicotine produced a very modest increase in spike rate in the coupled ganglion cell $(n=3)$, but dramatically increased spiking in the uncoupled cell $(n=3)$, much like that of ON-OFF DS ganglion cells (Kittila and Massey, 1997). This is shown in Figure 10D,E. This is somewhat consistent with the findings of Ackert et al. (2009), where the cholinesterase inhibitor neostigmine did not significantly increase firing in their coupled ON DS ganglion cells. Their recordings were also made in the presence of L-APB and picrotoxin to unmask a directional OFF response whose directionality was blocked by the neostigmine. In any case, stimulation of our coupled ON DS ganglion cells by nicotine did not lead to dramatically increased spiking as in uncoupled ON DS ganglion cells and ON-OFF DS ganglion cells, consistent with its stratification outside the cholinergic band. This is again evidence for physiological differences between the proposed two types of ON DS ganglion cell as well as suggesting that the transient coupled ON DS ganglion cell ramifies outside the cholinergic band, or has much less sensitivity to acetylcholine, or both.

The response to moving bars of light was similar to that described previously (Barlow et al., 1964; Oyster and Barlow 1967; He and Masland, 1999; Ackert et al., 2006; Kanjhan and Sivyer, 2010) for both the coupled and uncoupled ON DS ganglion cell types. Fifty micronwide slits of light were moved across the receptive fields of ON DS ganglion cells of each of the two types. The direction of motion was varied in $45^{\circ}$ increments from 0 to $315^{\circ}$. Both types preferred velocities of about $100 \mu \mathrm{m} / \mathrm{s}$, which is slower than the preferred velocity of ON-OFF DS ganglion cells. Figure 10F shows spiking patterns for an example of the uncoupled and coupled types.

The preferred orientation was determined from relative response rates of these directional motions and plotted in Figure 10G. The results indicated that the preferred axes of motion fell into three cardinal directions that were the same for the two types of ON DS ganglion cell, as well as those reported previously in the literature (e.g., Oyster and Barlow 1967; Ackert et al., 2006). There was no significant difference between the average degree of selectivity between the uncoupled type (mean DSI $=0.66 \pm 0.27$ ) and the coupled type (mean DSI $=0.67 \pm 0.30$ ).

\section{DISCUSSION}

For decades, ON DS ganglion cells in the rabbit retina have been described as a single type with three subclasses of preferred motion. We have demonstrated that ON DS ganglion cells in reality are actually composed of two distinctly different morphological types with associated differences in physiological response. Our results are similar and complementary to a study recently published by Kanjhan and Sivyer (2010). We will adopt their terminology of "sustained" versus "transient" types, although we will add the coupled/ uncoupled distinction at times in this article for clarity.

The transient (coupled) type has been recently characterized by Bloomfield and coworkers (Ackert et al., 2006, 2009) and may be equivalent to the ON parasol cell described by Roska et al. (2006), which is transient, and has inhibitory inputs reminiscent of polyaxonal amacrine cells such as those described here and in Ackert et al. (2009). The other, sustained (uncoupled) type has been commonly encountered previously (Amthor et al., 1989; Famiglietti, 1992; He and Masland, 1998). It may also correspond to the ganglion cell suggested by Roska et al. (2006) to be an ON delta, as it ramifies similarly and is more sustained than the ON parasol. This cell showed two distinct temporal regions of strong spiking. While the first region occurs with a relatively short latency, the second region roughly corresponds to the extended latency we have found in our uncoupled ON DS ganglion cells. 
In their survey of rabbit ganglion cells, Rockhill et al. (2002) referred to the ON DS ganglion cell as the G10. It may be that the G10 ganglion cell must be subdivided into the two types we have encountered. Interestingly, their two G10 micrographs may show both of our types. To reiterate, these cell types can be reliably discriminated on the basis of 1) their branching patterns; 2) tracer coupling; 3,4 ) the latency and relative transience of the spiking responses; 5) their stratification depth; and 6) their response to nicotine (Fig. 10C). The nicotine response of the sustained uncoupled ON DS ganglion cell is much like that of ONOFF ganglion cells (Kittila and Massey, 1997; Zhang et al., 2005), while nicotine produces very modest increases in firing in transient coupled ON DS ganglion cells (Fig. 10D), consistent with their stratification above the cholinergic band.

The last two measures, stratification depth and cholinergic response, speak to the mechanism of directional selectivity, which considerable research (e.g., Euler et al., 2002; Fried et al., 2002; Zhou and Lee, 2008; Lee et al., 2010; Wei et al., 2010; Yonehara et al., 2011) has indicated depends critically on a GABAergic mechanism produced by asymmetric null-side inputs from starburst amacrine cells, which release GABA as well as acetylcholine (O'Malley and Masland, 1989). These results readily apply to ON-OFF DS ganglion cells and the uncoupled ON DS ganglion cell, which ramify in the ON cholinergic band and cofasciculate with the cholinergic processes. Similar results have been reported for the mouse retina, where the ON DS ganglion cell has a similar morphology to the uncoupled sustained DS GC reported here (Sun et al., 2006; Yonehara et al., 2010).

In contrast, the coupled ON DS ganglion cell primarily ramifies distal to the cholinergic band, does not cofasciculate with starburst dendrites, and has a minor response to nicotine. Although its directional response is also blocked by GABA (Ackert et al., 2006), our results suggest that DS may arise from mechanisms that are not dependent on starburst amacrine cells. (The cholinergic sensitivity of an OFF DS response unmasked by GABA antagonists (Ackert et al., 2009) may arise from ramification of the axon-bearing amacrine cells in the OFF cholinergic band.)

The stratification of the well-coupled ON DS ganglion cell is of particular interest. While these transient and sustained ON DS layers appear to be close, adjacent layers are actually separated by $1-3 \mu \mathrm{m}$. The coupled ON DS cell and the starburst amacrine cells clearly occupy different substrata and therefore they lack opportunity for much direct synaptic contact. While the differential sensitivity to acetylcholine could result from a different complement of cholinergic receptors, the GABA effects would have to be produced by a different amacrine cell or paracrine transmission of GABA from the starburst, which seems unlikely (Yonehara et al., 2010). This suggests, then, that there may be additional mechanisms to generate directional selectivity, as also seen in an OFF ganglion cell in the mouse reported to be DS (Kim et al., 2008).

It is interesting that these two types have not been differentiated prior to the work of Kanjhan and Sivyer (2010) and ourselves. Buhl and Peichl (1986) injected tracer into the medial terminal nucleus (MTN) of the accessory optic system, while Pu and Amthor (1990) injected tracer into the nucleus of the optic tract (NOT), followed by dye-injection of the labeled ganglion cells. They generally seem to have considered the two types as variations of a single type, although Pu and Amthor (1990) commented on some morphological differences in their population, including number of crossings and number of fine terminal dendrites. No recordings were made in these studies, the two types have overlapping size distributions, and both studies were conducted prior to the common use of Neurobiotin as a gap junction-permeant tracer. In retrospect, both types may be represented in the drawings of both groups. The possibility that the morphology of the transient (coupled) type is 
represented in the Pu and Amthor (1990) study but not the Buhl and Peichl (1986) study might mean that the "coupled" type preferentially projects to the NOT and not to the MTN.

Buhl and Peichl (1986) published six drawings of filled MTN-projecting ganglion cells. Pu and Amthor (1990) published drawings of many more cells. Many of these may be incompletely stained or drawn. Nevertheless, clear examples of the more dense uncoupled type can be found, while other drawings suggesting the coupled type was also found, subject to the proviso that the branching pattern is fully represented.

The dendritic arbors of six ON DS ganglion cells representing the variation in the literature were analyzed according to the two measures plotted in Figure 8B. Using the Buhl and Peichl (1986) drawings, a putative uncoupled ON DS ganglion cell fell clearly within the parameter space of our uncoupled ON DS ganglion cells (Fig. 8B; inverted triangle), while one resembling our coupled ON DS ganglion cell narrowly fell within their parameter space (square). Similarly, cell L from figure 7 of Pu and Amthor (1990) was well within the parameter space of our coupled ON DS ganglion cells (checkered circle), while their cell F of figure 7 (star) was well within the parameter space of our uncoupled ON DS ganglion cells. Similarly, the ON DS ganglion cell shown by Kanjhan and Vaney (2008; fig. 1D; X in our Fig. 8) clearly resembled our uncoupled ON DS ganglion cell and the drawing of a coupled ON DS ganglion cell from Ackert et al. (2006) was narrowly within the parameter space of our coupled ON DS ganglion cells (diamond). On balance, this comparison of morphologies makes it quite clear that uncoupled ON DS ganglion cells share the morphology of cells that project to the MTN. It is possible that the coupled ON DS ganglion cells also project to this area, or to this area as well as other areas, but the results are more equivocal. Results in mice from Yonehara et al. (2009) are suggestive of different projections for ON DS ganglion cells with differing cardinal axes.

Although the multivariate analysis clearly establishes that the coupled and uncoupled ON DS ganglion cells consist of two separate and distinct types, they still retain certain similarities in their physiological responses to moving bars: 1) the directional axes of preferred motion fall into the same three cardinal axes (Fig. 10G); and 2) the preferred width and rate of speed of bar motion is about $100 \mu \mathrm{m} / \mathrm{s}$, comparable to previous studies of ON DS ganglion cells, but slower than that of ON-OFF DS ganglion cells (Oyster, 1968).

Why would there be two different types of ON DS ganglion cell, with similar orientation axes and speed preferences that project to the same location, or indeed, different locations? The reasons may arise from the differences we have shown, most notably the latency, transience and coupling patterns. The latency and transient/sustained characteristics of spiking might convey different sorts of information, while the coupled axonbearing amacrine cells could provide inputs from distances well beyond the dendritic field of the coupled ON DS. These amacrine cells do in fact appear to be critically involved in an OFF DS response of this cell type that can be unmasked via $\mathrm{GABA}_{\mathrm{A}}$ inhibition (Ackert et al., 2009).

\section{Acknowledgments}

Grant sponsor: National Institutes of Health (NIH); Grant numbers: EY 65015 (to S.C.M.), EY 10121 (to S.L.M.), and Vision Core Grant EY10608; Grant sponsor: unrestricted award from Research to Prevent Blindness to the Department of Ophthalmology and Visual Science, University of Texas at Houston Health Science Center. 


\section{LITERATURE CITED}

Ackert JM, Wu SH, Lee JC, Abrams J, Hu EH, Perlman I, Bloomfield SA. Light-induced changes in spike synchronization between coupled ON direction selective ganglion cells in the mammalian retina. J Neurosci. 2006; 26:4206-4215. [PubMed: 16624941]

Ackert JM, Farajian R, Völgyi B, Bloomfield SA. GABA blockade unmasks an OFF response in ON direction selective ganglion cells in the mammalian retina. J Physiol. 2009; 587:4481-4495. [PubMed: 19651763]

Amthor FR, Oyster CW, Takahashi ES. Morphology of on-off direction-selective ganglion cells in the rabbit retina. Brain Res. 1984; 298:187-190. [PubMed: 6722555]

Amthor FR, Takahashi ES, Oyster CW. Morphologies of rabbit retinal ganglion cells with complex receptive fields. J Comp Neurol. 1989; 280:97-121. [PubMed: 2918098]

Barlow HB, Hill RM, Levick WR. Retinal ganglion cells responding selectively to direction and speed of image motion in the rabbit. J Physiol. 1964; 173:377-407. [PubMed: 14220259]

Brainard DH. The psychophysics toolbox. Spatial Vision. 1997; 10:443-446. [PubMed: 9176954]

Buhl EH, Peichl L. Morphology of rabbit retinal ganglion cells projecting to the medial terminal nucleus of the accessory optic system. J Comp Neurol. 1986; 253:163-174. [PubMed: 3793989]

Euler T, Detwiler PB, Denk W. Directionally selective calcium signals in dendrites of starburst amacrine cells. Nature. 2002; 418:845-852. [PubMed: 12192402]

Famiglietti EV. Dendritic co-stratification of ON and ON-OFF directionally selective ganglion cells with starburst amacrine cells in the rabbit retina. J Comp Neurol. 1992; 324:322-335. [PubMed: 1383291]

Fried SI, Munch TA, Werblin FS. Mechanisms and circuitry underlying directional selectivity in the retina. Nature. 2002; 420:411-414. [PubMed: 12459782]

He S, Masland RH. ON direction-selective ganglion cells in the rabbit retina: dendritic morphology and pattern of fasciculation. Vis Neurosci. 1998; 15:369-375. [PubMed: 9605536]

Hoshi H, Mills SL. Components and properties of the G3 ganglion cell circuit in the rabbit retina. J Comp Neurol. 2009; 513:69-82. [PubMed: 19107780]

Hoshi H, O’Brien J, Mills SL. A novel fluorescent tracer for visualizing coupled cells in neural circuits of living tissue. J Histochem Cytochem. 2006; 54:1169-1176. [PubMed: 16864895]

Kanjhan R, Sivyer B. Two types of ON DS ganglion cells in rabbit retina. Neurosci Lett. 2010; 483:105-109. [PubMed: 20678546]

Kanjhan R, Vaney DI. Semi-loose seal Neurobiotin electroporation for combined structural and functional analysis of neurons. Pflugers Arch. 2008; 457:561-568. [PubMed: 18600343]

Kim IJ, Zhang Y, Yamagata M, Meister M, Sanes JR. Molecular identification of a retinal cell type that responds to upward motion. Nature. 2008; 452:478-482. [PubMed: 18368118]

Kittila CA, Massey SC. Pharmacology of directionally selective ganglion cells in the rabbit retina. J Neurophys. 1997; 77:675-689.

Lee S, Kim K, Zhou ZJ. Role of ACh-GABA cotransmission in detecting image motion and motion direction. Neuron. 2010; 68:1159-1172. [PubMed: 21172616]

Masland RH. The fundamental plan of the retina. Nat Neurosci. 2001; 4:877-886. [PubMed: 11528418]

Mills SL, Hoshi H. Two distinct types of directionally-selective ganglion cells in the rabbit retina. Invest Opthalmol Vis Sci. 2010; 51 ARVO E-Abstract 1870.

Mills SL, Xia XB, Hoshi H, Firth SI, Rice ME, Frishman LJ, Marshak DW. Dopaminergic modulation of tracer coupling in a ganglion-amacrine cell network. Visual Neurosci. 2007; 24:593-608.

O'Malley DM, Masland RH. Co-release of acetylcholine and gamma-aminobutyric acid by a retinal neuron. Proc Natl Acad Sci U S A. 1989; 86:3414-3418. [PubMed: 2566171]

Oyster CW. The analysis of image motion by the rabbit retina. J Physiol. 1968; 199:613-635. [PubMed: 5710424]

Oyster CW, Barlow HB. Direction-selective units in rabbit retina: distribution of preferred directions. Science. 1967; 155:841-842. [PubMed: 6019094] 
Pelli DG. The VideoToolbox software for visual psychophysics: transforming numbers into movies. Spatial Vision. 1997; 10:437-442. [PubMed: 9176953]

Pow DV, Wright LL, Vaney DI. The immunocytochemical detection of amino-acid neurotransmitters in paraformaldehyde-fixed tissues. J Neurosci Methods. 1995; 56:115-123. [PubMed: 7752677]

$\mathrm{Pu}$ ML, Amthor FR. Dendritic morphologies of retinal ganglion cells projecting to the nucleus of the optic tract in the rabbit. J Comp Neurol. 1990; 302:657-674. [PubMed: 1702123]

Rockhill RL, Daly FJ, MacNeil MA, Brown SP, Masland RH. The diversity of ganglion cells in a mammalian retina. J Neurosci. 2002; 22:3831-3843. [PubMed: 11978858]

Roska B, Molnar A, Werblin F. Parallel processing in retinal ganglion cells: how integration of spacetime patterns of excitation and inhibition form the spiking output. J Neurophysiol. 2006; 95:3810 3822. [PubMed: 16510780]

Sholl DA. Dendritic organization in the neurons of the visual and motor cortices of the cat. J Anat. 1953; 87:387-406. [PubMed: 13117757]

Sun W, Deng Q, Levick WR, He S. ON direction-selective ganglion cells in the mouse retina. J Physiol. 2006; 576:197-202. [PubMed: 16901944]

Vaney, DI.; Collin, SP.; Young, HM. Dendritic relationships between cholinergic amacrine cells and direction-selective retinal ganglion cells. In: Weiler, R.; Osborne, NN., editors. Neurobiology of the inner retina. Vol. H31. Berlin: Springer; 1989. p. 157-168.

Wässle H. Parallel processing in the mammalian retina. Nat Rev Neurosci. 2004; 5:747-757. [PubMed: 15378035]

Wei W, Hamby AM, Zhou K, Feller MB. Development of asymmetric inhibition underlying direction selectivity in the retina. Nature. 2011; 469:402-406. [PubMed: 21131947]

Yonehara K, Ishikane H, Sakuta H, Shintani T, Nakamura-Yonehara K, Kamiji NL, Usui S, Noda M. Identification of retinal ganglion cells and their projections involved in central transmission of information about upward and downward image motion. PLoS ONE. 2009; 4:e4320. [PubMed: 19177171]

Yonehara K, Balini K, Noda M, Nagel G, Bamberg E, Roska B. Spatially asymmetric reorganization of inhibition establishes a motion-sensitive circuit. Nature. 2011; 469:407-410. [PubMed: 21170022]

Zhang J, Li W, Hoshi H, Mills SL, Massey SC. Stratification of alpha ganglion cells and ON/OFF directionally selective ganglion cells in the rabbit retina. Vis Neurosci. 2005; 22:535-549. [PubMed: 16212709]

Zhou ZJ, Lee S. Synaptic physiology of direction selectivity in the retina. J Physiol. 2008; 586:43714376. [PubMed: 18617561] 


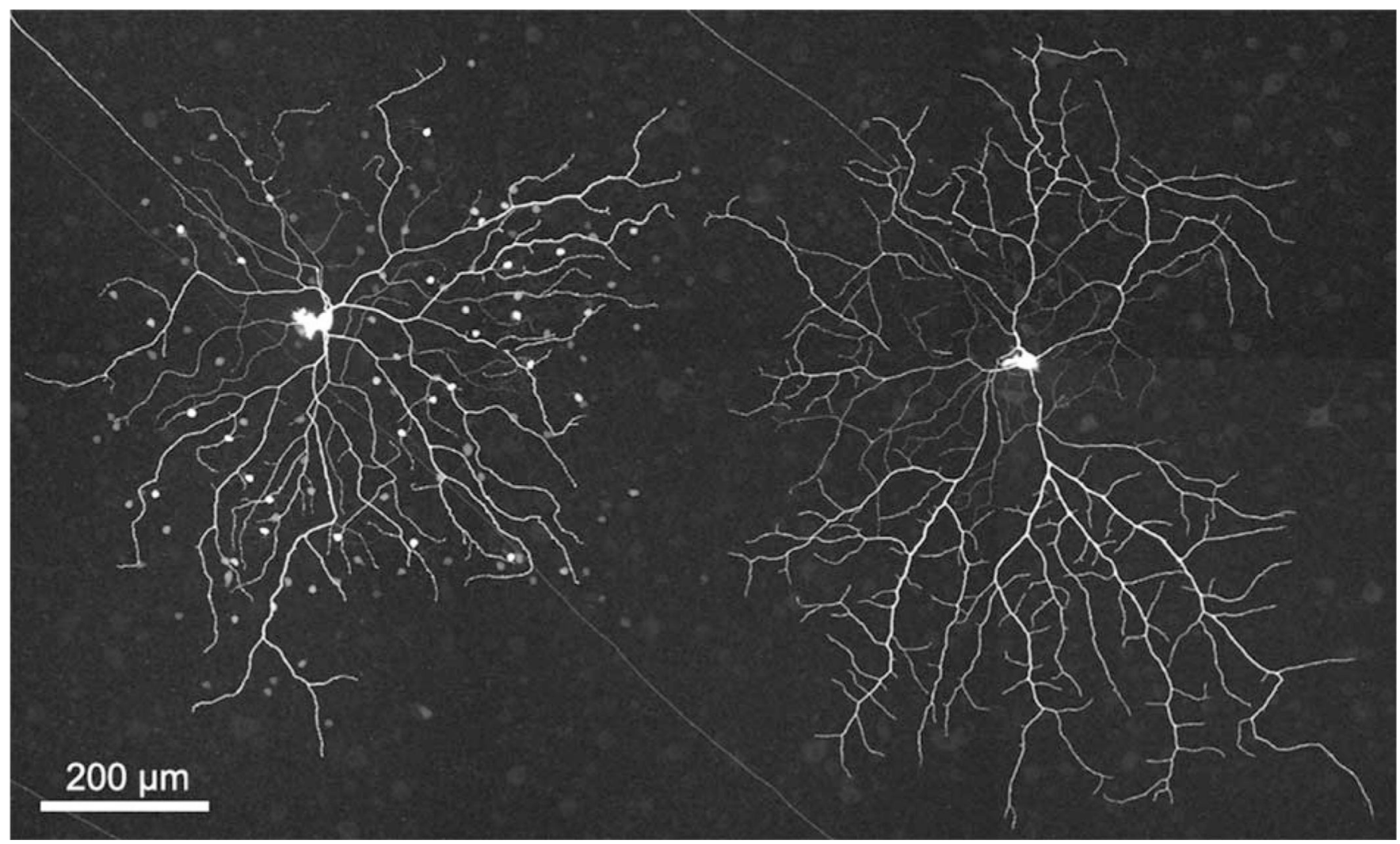

Figure 1.

Two morphologically distinct types of ganglion cell with ON DS physiology are found in the rabbit retina. Neurobiotin-staining reveals that one type (left) is extensively coupled to two types of amacrine cell, while the other type (right) is always uncoupled. The image is a stack of $35 \times 1.0 \mu \mathrm{m}$ optical sections. 

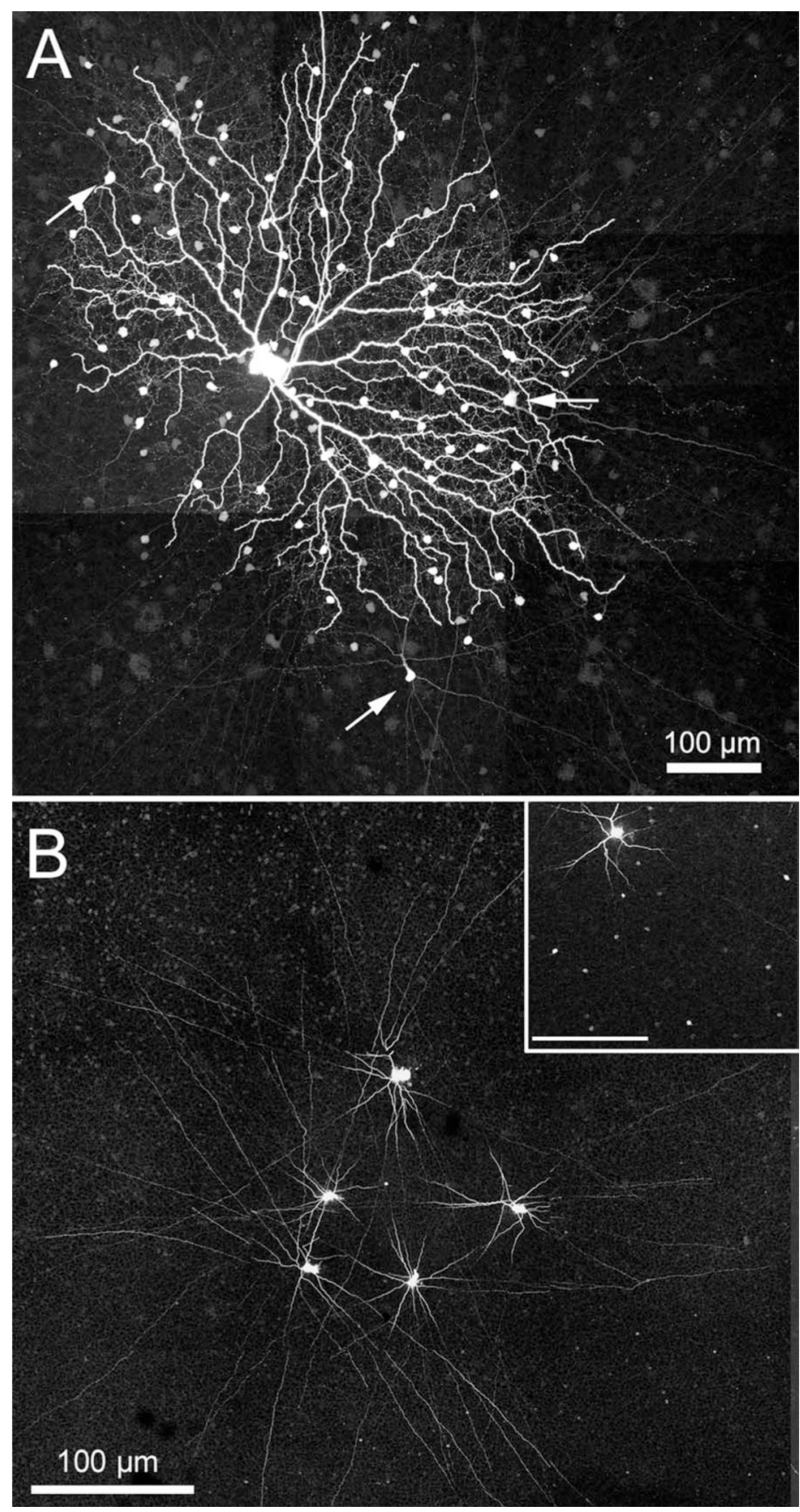

Figure 2.

A: A photomontage $(35 \times 1.0 \mu \mathrm{m}$ optical sections $)$ of an ON DS ganglion cell is shown where the processes and somatic morphology of the axon-bearing amacrine cell can be clearly seen (arrows). B: Five coupled amacrine cells were stained by Neurobiotin injection following visualization of the nuclei of the coupled amacrine cells by injection of Popro1 into a coupled ON DS ganglion cell. All of the injected amacrine cells were axon-bearing. This panel is a photomontage of $14 \times 1.0 \mu \mathrm{m}$ optical sections. Inset: A photomontage of 17 $\times 1.0 \mu \mathrm{m}$ optical sections shows numerous coupled somas in the IPL resulting from Neurobiotin injection into 14 axon-bearing amacrine cells visualized by Popro1-injection. 
The figure has been cropped to show only a single tracer-injected amacrine cell. Inset scale bar $=100 \mu \mathrm{m}$. 

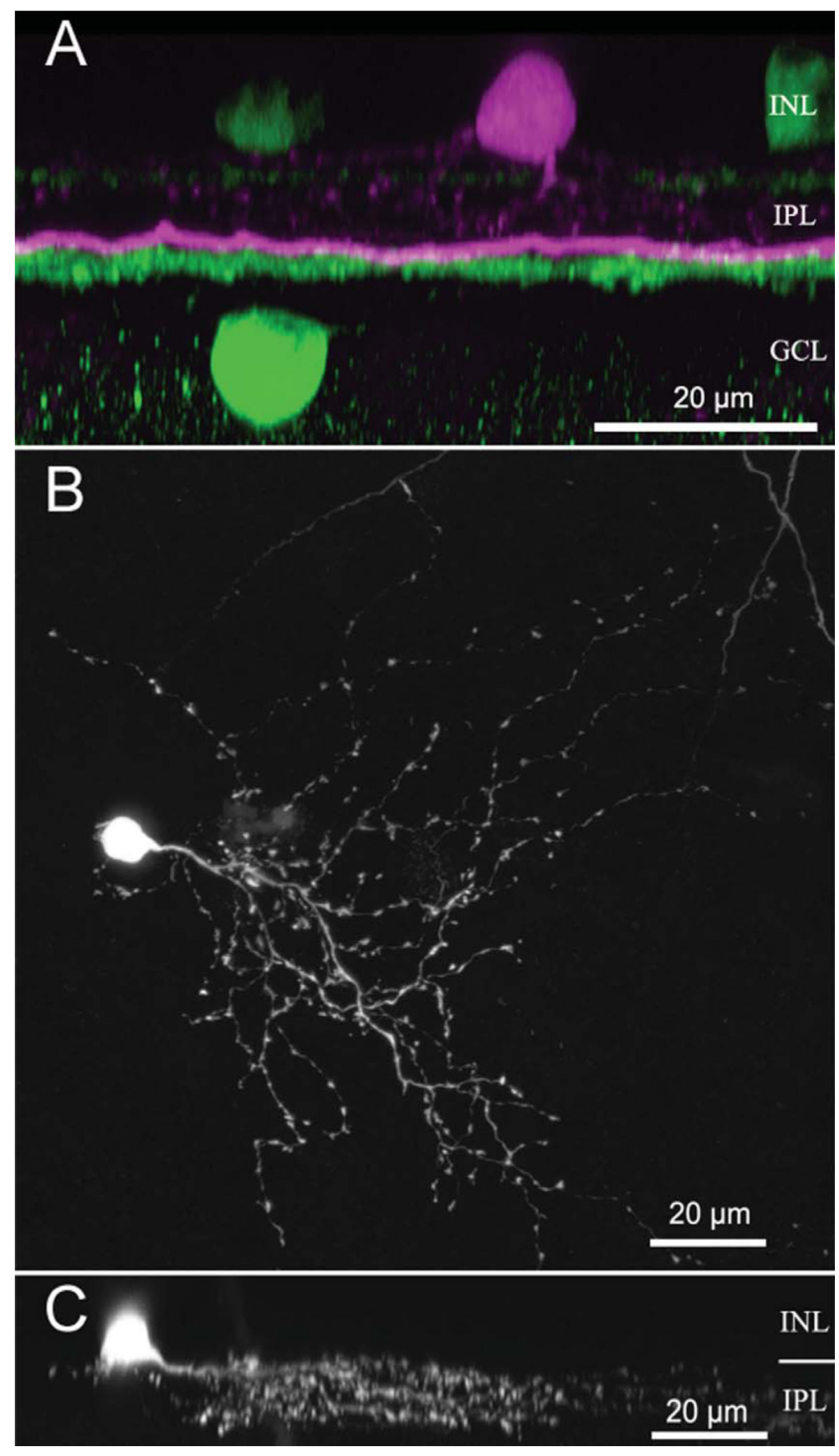

Figure 3.

A: A diffuse multistratified amacrine cell is visualized following Neurobiotin injection into a coupled ON DS ganglion cell. A thicker, brightly stained dendrite from the ganglion cell (magenta) is shown ramifying just distal to the ON cholinergic amacrine cell band (green), while the thin, dimmer amacrine cell processes (also magenta) branch from the distal portion of the IPL down to the ON cholinergic band. B: A diffuse multistratified amacrine cell was stained with Neurobiotin following Popro1 injection into an ON DS ganglion cell. The knotty, tangled morphology is clearly seen in this flatmount view. C: A z-reconstruction of the same amacrine cell in (B) shows the vertical extent of this amacrine cell type. Panel A is a stack of $10 \times 0.3 \mu \mathrm{m}$ optical sections; panel $\mathrm{B}$ and $\mathrm{C}$ are $48 \times 0.3 \mu \mathrm{m}$ optical sections. 

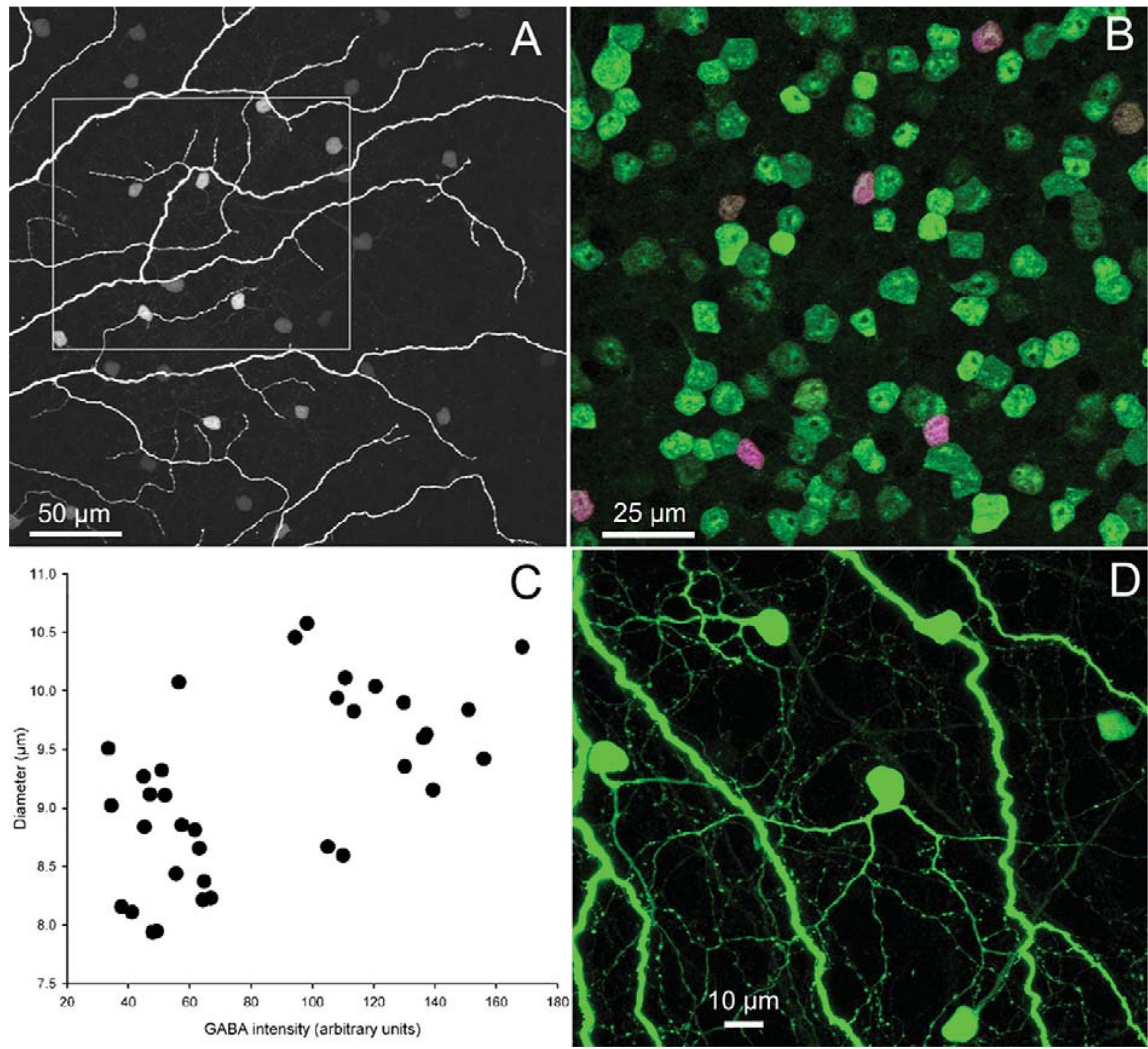

Figure 4.

Both types of amacrine cell Neurobiotin-coupled (magenta) to coupled ON DS ganglion cells (A) are immunopositive for GABA (green). All coupled amacrine cells therefore are double-labeled and appear purple (B). Panel A is $12 \times 1 \mu \mathrm{m}$ optical section, while B was made from $30 \times 0.3 \mu \mathrm{m}$ optical sections. C: For each amacrine cell in (B), its soma diameter was plotted against the staining intensity of the GABA antibody. The GABA measure separates the two populations into two nonoverlapping distributions and reveals an average size difference between the somas of the two populations. D: Intense staining of the diffuse multistratified amacrine cells indicates that they are well coupled to the injected ganglion cell, while poorly coupled to one another (Fig. 3B). 

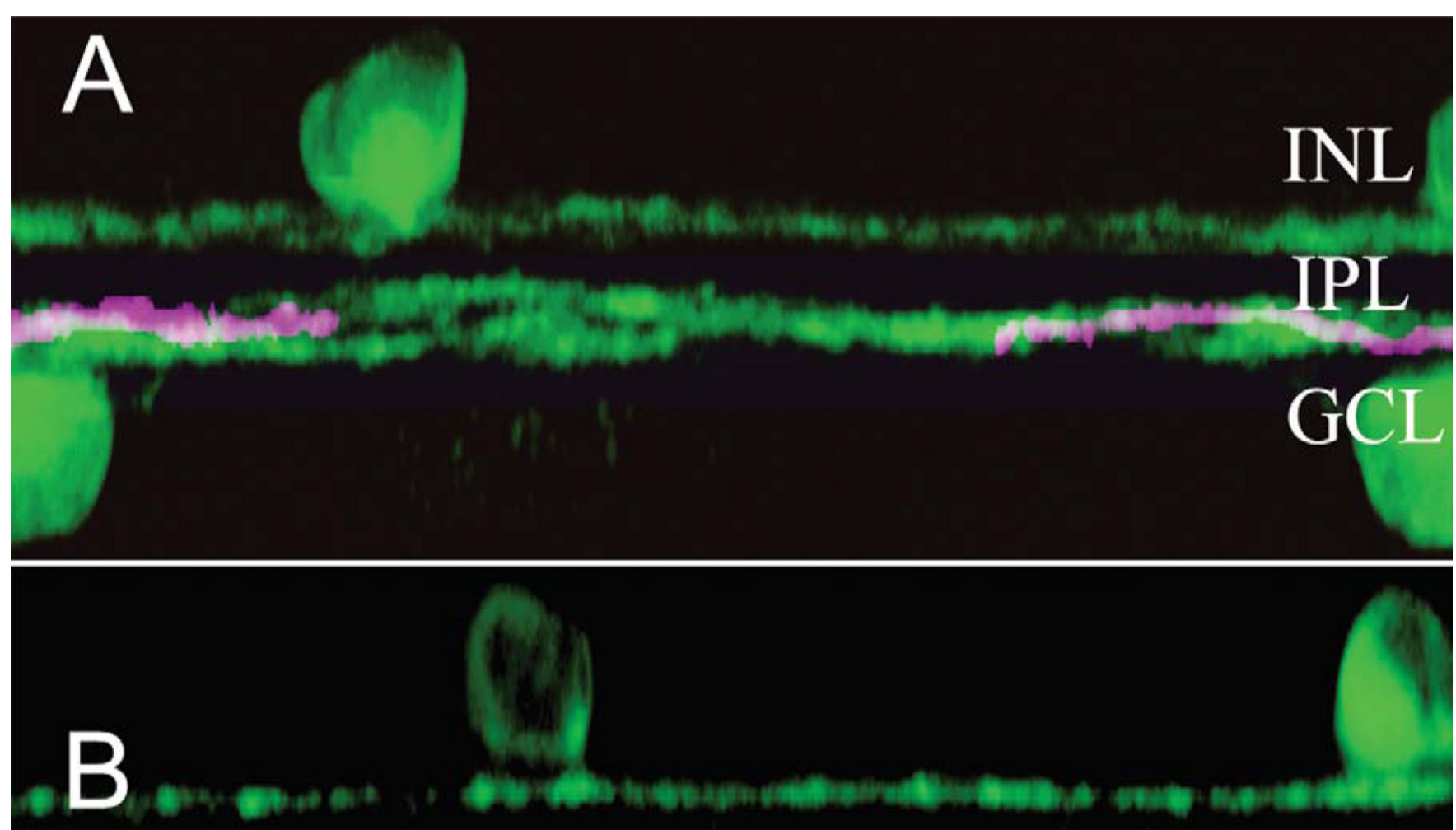

Figure 5.

A: The dendritic arbor of uncoupled ON DS ganglion cells (magenta) ramifies within the ON ChAT band. B: The dendritic arbor of coupled ON DS ganglion cells (magenta) ramifies primarily just distal of the ON ChAT band (green). The arrow marks a portion of the axon of this cell. These panels are $\mathrm{z}$-reconstructions formed by rotating xy images using $108 \times 0.3$ $\mu \mathrm{m}$ optical sections. 

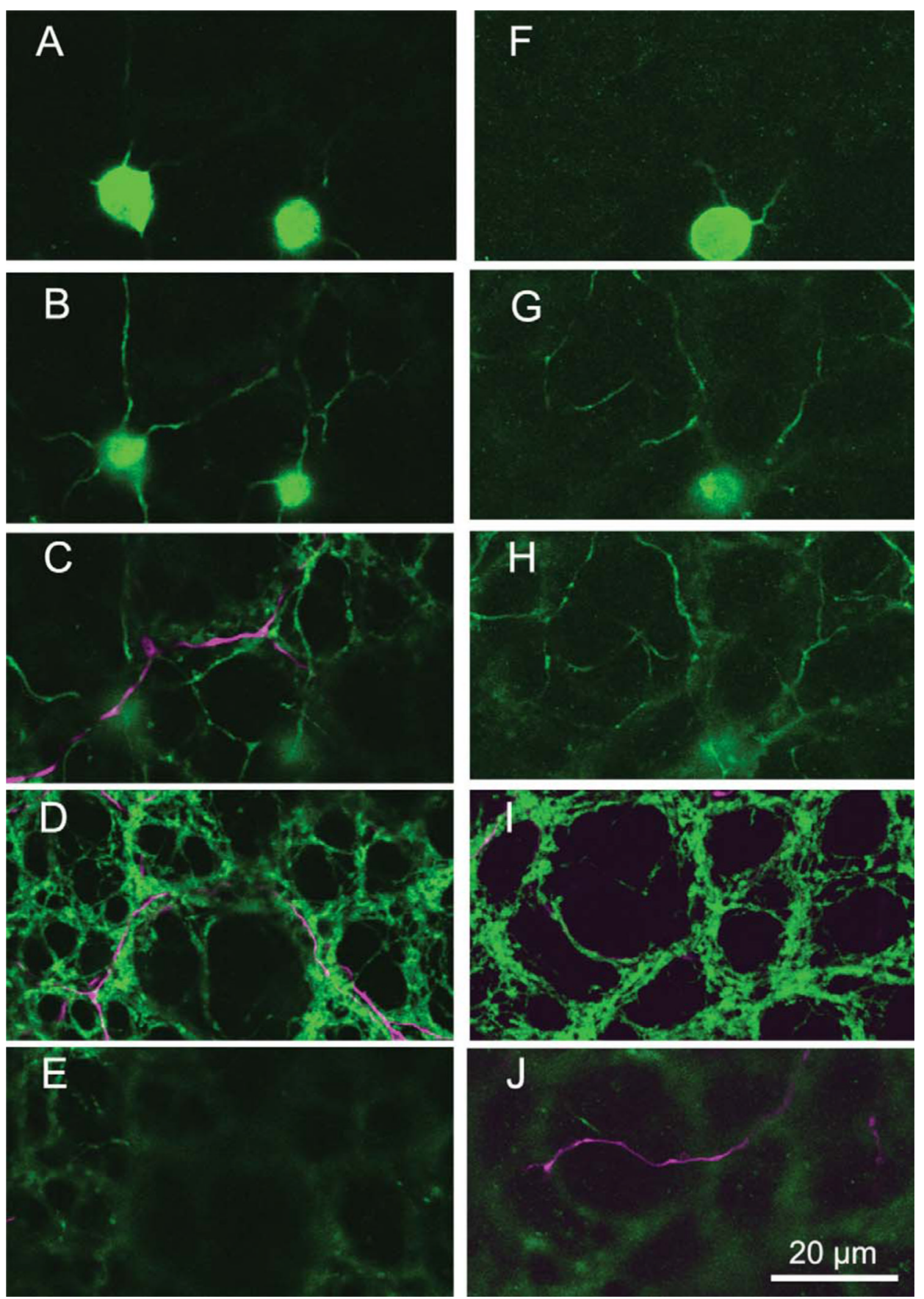

Figure 6.

A series of single $0.3-\mu \mathrm{m}$ optical sections shows the differences in stratification depth for an uncoupled ON DS ganglion cell (left) and a coupled ON DS ganglion cell (right). Somas of ON cholinergic amacrine cells (green) stained by the ChAT antibody appear in the ganglion cell layer $(\mathbf{A , F})$; their initial branches appear at about $80 \%$ depth in the IPL $(\mathbf{B , G})$. Branches of the ON DS ganglion cells (magenta) appear at different depths. The uncoupled ON DS ganglion cell dendrites appear with the full branching of the dendritic arbor of the cholinergic amacrine cells $(\mathbf{C}, \mathbf{D})$, but not above $(\mathbf{E})$. Dendrites of the coupled ON DS ganglion cell appear at the top of the cholinergic band (I) and slightly above it (J). 


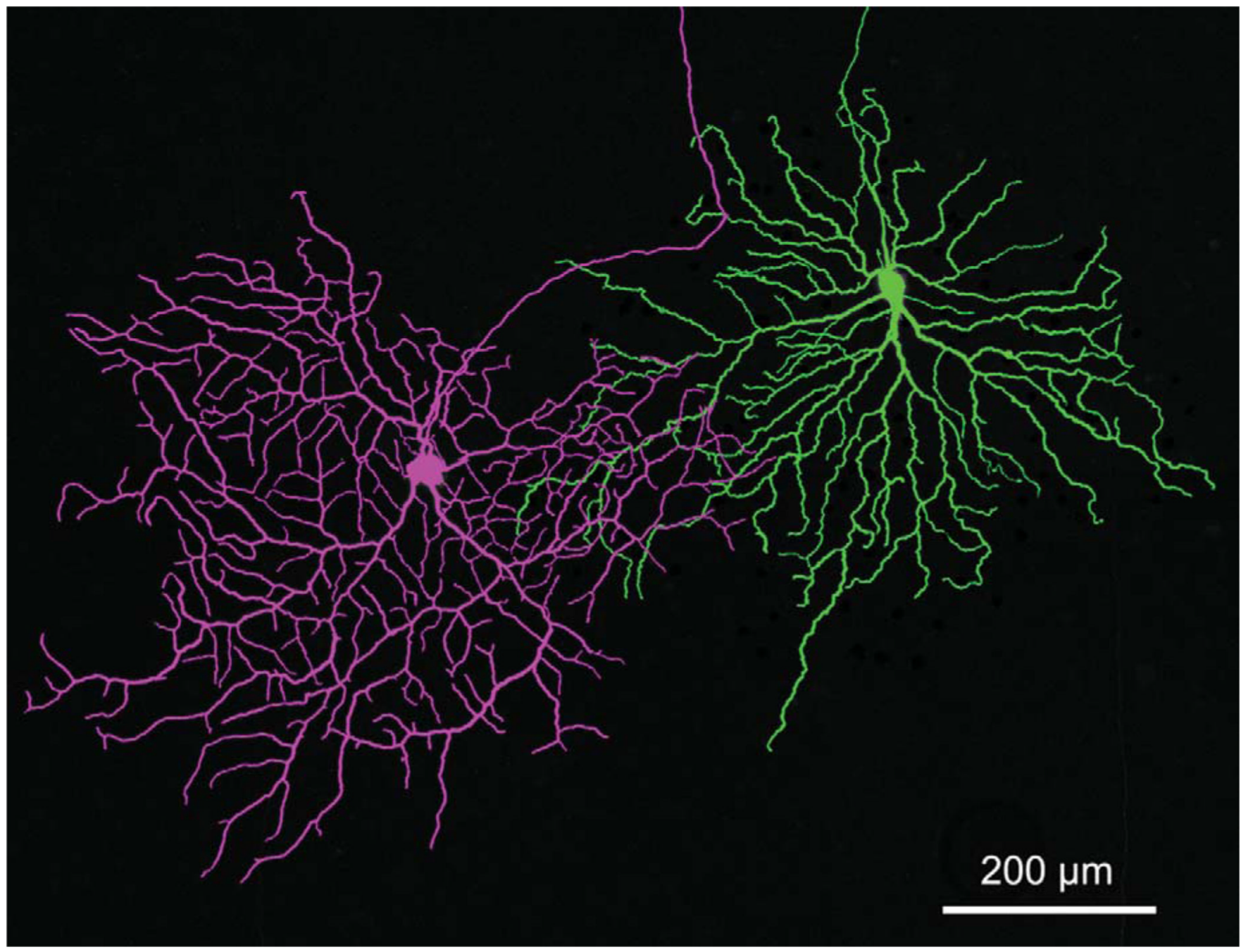

Figure 7.

An overlapping pair of coupled (green) and uncoupled (magenta) ON DS ganglion cells. The coupled amacrine cells were erased in Adobe Photoshop to facilitate comparison of the dendritic morphology. The uncoupled ON DS ganglion cell is clearly more profusely branched, and with branch angles greater than those of the coupled ON DS ganglion cell. The micrograph is $35 \times 1 \mu \mathrm{m}$ optical sections. 

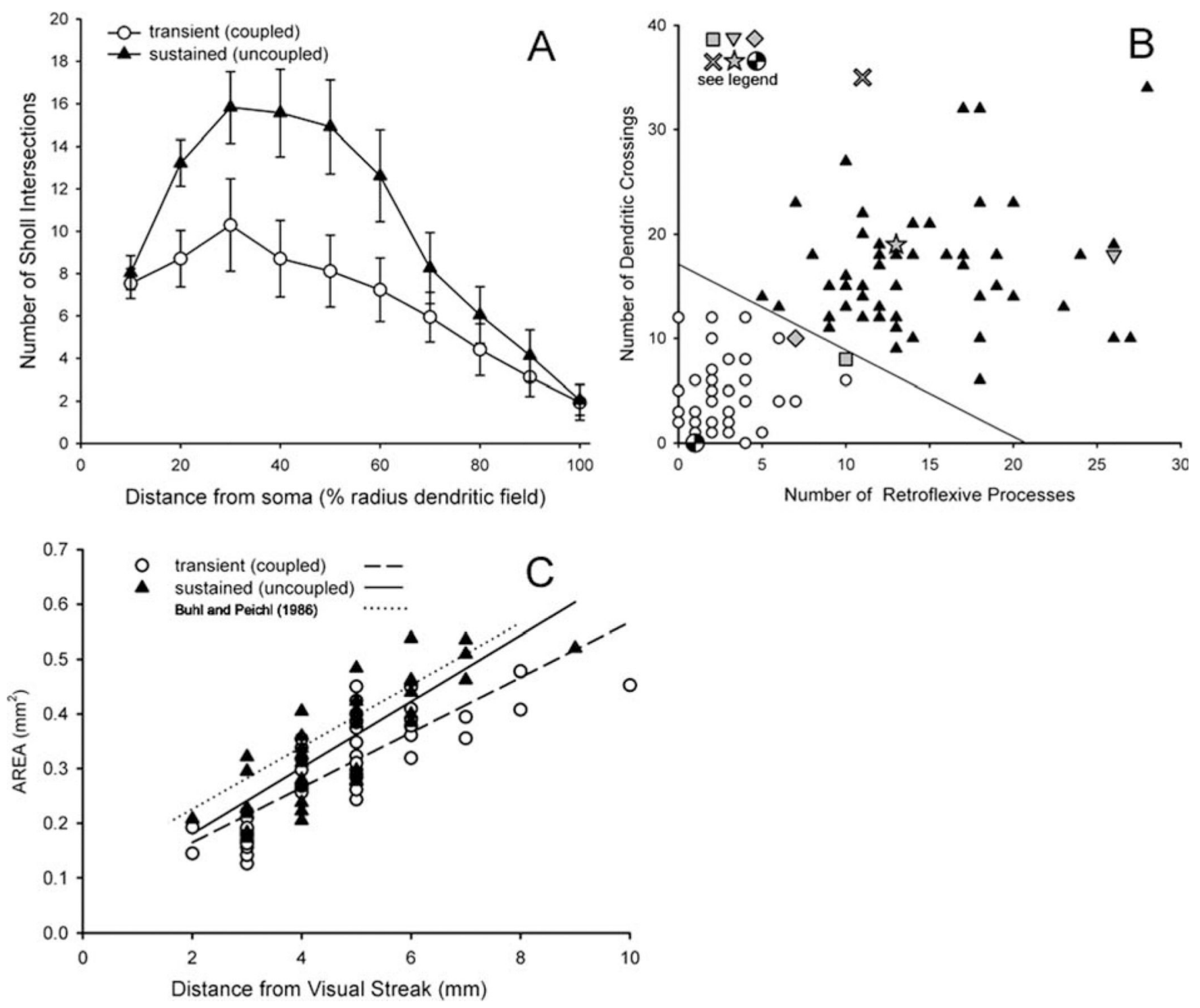

Figure 8.

Objective quantitative measurements form populations that separate the uncoupled and uncoupled ON DS ganglion cells into two groups independently of coupling. A: An automated Sholl analysis counted number of intersections of dendritic processes with the perimeters of concentric circles placed at 10- $\mu \mathrm{m}$ intervals from the soma. The distances were normalized by the radius of the cell to facilitate comparison across eccentricities. The density of uncoupled ON DS ganglion cell dendrites was much higher than that of coupled ON DS ganglion cell dendrites. Error bars $= \pm 1 \mathrm{SE}$. B: A plot of the number of retroflexive processes vs. the number of times a cell's dendrites cross one another fully separates the populations (unfilled circles: transient coupled ON DS ganglion cell; filled triangles: uncoupled sustained ON DS ganglion cell). Six cells whose dendritic morphology has been previously published were analyzed in parallel. These are: checkered circle (Pu and Amthor, 1990; fig. 7L); square (Buhl and Peichl, 1986; fig. 10, third from top); diamond (Ackert et al., 2006; fig. 1E2); star (Pu and Amthor, 1990; fig. 7F); X (Kanhjan and Vaney, 2008); inverted triangle (Buhl and Peichl, 1986; fig. 10, bottom). C: The dendritic field area increases for each cell in the ventral retina as a function of distance from the visual streak. 
The lines are linear least squares fits to each data set as labeled. The size differences are not significant. 


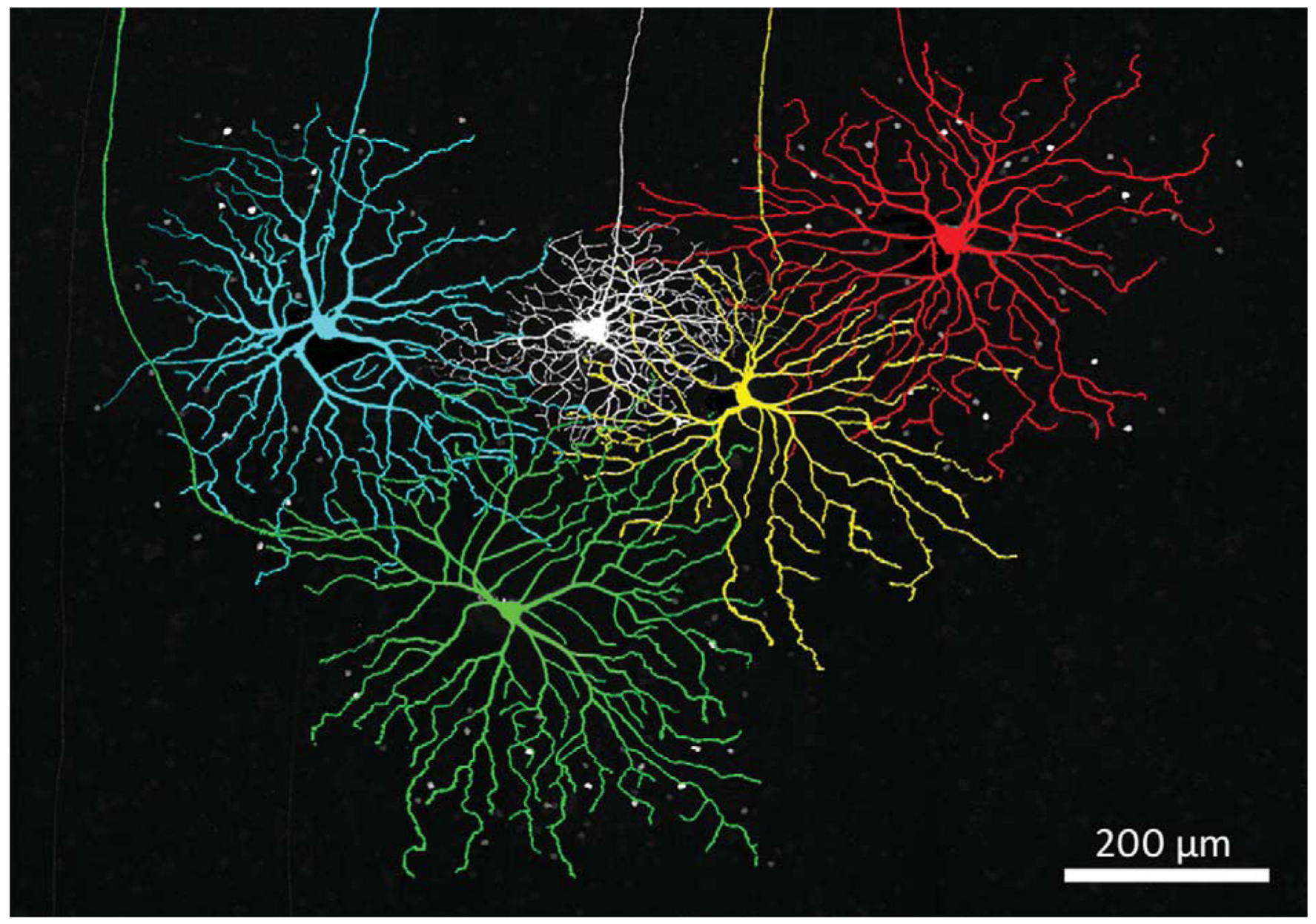

Figure 9.

Four Neurobiotin-injected coupled ON DS ganglion cells surrounding an ON-OFF DS ganglion cell (white) show the relative size of these two cell types. The ganglion cells were colored in Adobe Photoshop for clarity. The micrograph is constructed from $35 \times 1.0 \mu \mathrm{m}$ optical sections. These four ON DS ganglion cells are not necessarily nearest neighbors. 
A
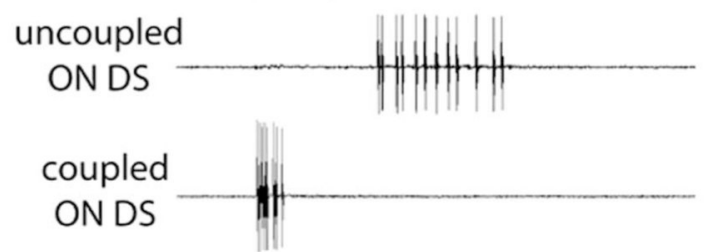

B
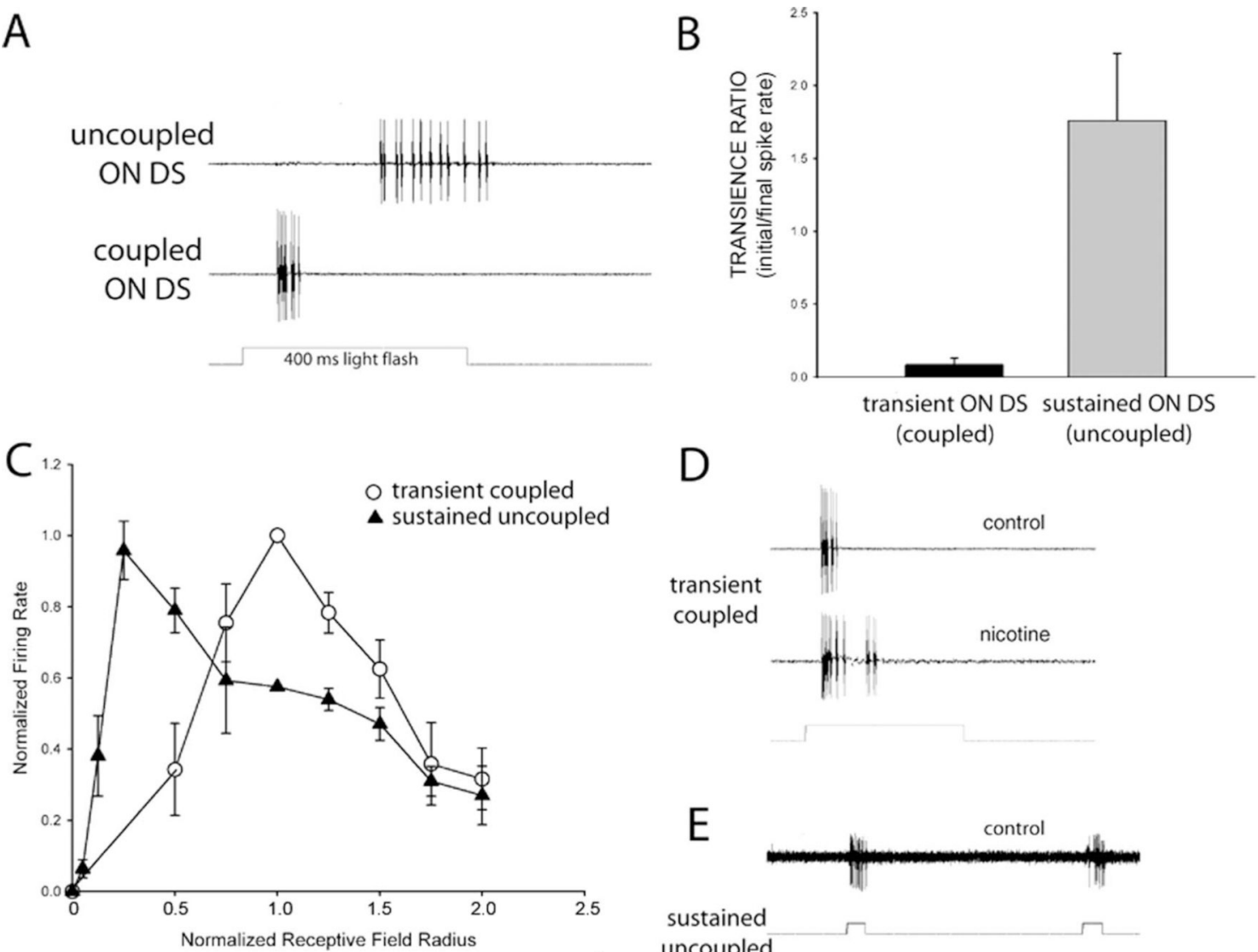

D (coupled) (uncoupled)

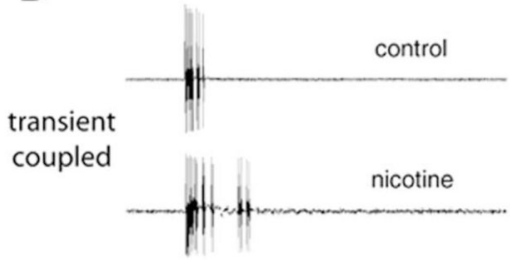

$\mathrm{F}$
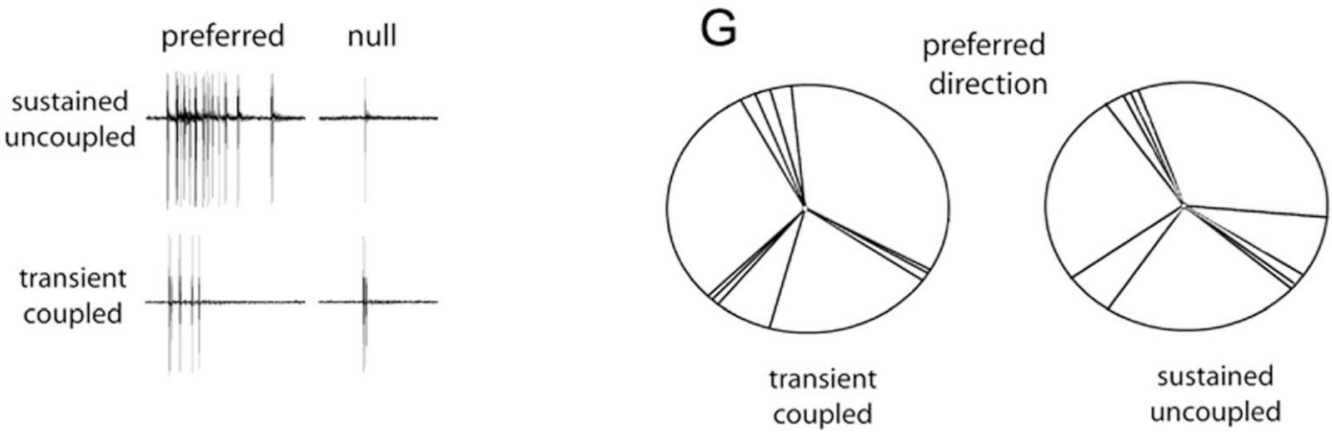

Figure 10.

The physiology of coupled and uncoupled ON DS ganglion cells correlates with their morphological characteristics. A,B: The uncoupled ON DS ganglion cell displays a sustained response to spots of light, while coupled ON DS ganglion cells are transient and of short latency. C: Receptive field profiles to spots of increasing size indicate that the spike rate of transient coupled ON DS ganglion cells peaks at about the dendritic field size, while that of sustained uncoupled ON DS ganglion cells peaks before 50\% of the dendritic field is fully illuminated. D,E: Nicotine $(2 \mu \mathrm{M})$ has a minor effect on the firing of coupled ON DS ganglion cells (D), but produces uncontrollable firing in uncoupled ON DS ganglion cells (E). The arrow marks the initial increase in firing in response to application of nicotine, 
about 30 seconds after addition to the perfusate. F: Both types show directional preference, with more firing in the preferred than null direction. G: The directional preference of coupled ON DS ganglion cells (left) and uncoupled ON DS ganglion cells (right) were similar to one another and the distribution of cardinal directions previously reported after reflection of the data to compensate for the absence of the lens in our paradigm. Bars moving in the ventral to dorsal direction are plotted at 12 o'clock. Light flashes were of 400 ms duration in all panels. 


\section{TABLE 1}

Antibodies Used and Their Immunogens, Suppliers, and Dilutions

\begin{tabular}{llll}
\hline Antigen & Immunogen & Manufacturer, species, type, catalog number & Dilution used \\
\hline Choline acetyltransferase & Human placental enzyme & Millipore (Billerica, MA) goat polyclonal \#AB144P & $1: 100$ \\
GABA & $\begin{array}{l}\text { Formaldehyde conjugate - porcine } \\
\text { thyroglobulin }\end{array}$ & $\begin{array}{l}\text { Immunosolution (Jesmond, NSW, AU) rabbit } \\
\text { polyclonal \#IG1004 }\end{array}$ & $1: 1,000$ \\
\hline
\end{tabular}

